\title{
An in-depth review of retrospective studies to assess the role of vascular brachytherapy for the treatment of complex patients with multiple risk factors for DES-ISR
}

\author{
Anika Mittal $^{1, *}$, Satvinder S Dhaliwal ${ }^{1,2,3,4}$, Devind Bhullar ${ }^{5}$, Joshua Dass $^{1,6}$ \\ ${ }^{1}$ Department of Radiation Oncology, Sir Charles Gairdner Hospital, 6009 Perth, Australia \\ ${ }^{2}$ Curtin Health Innovation Research Institute, Faculty of Health Sciences, Curtin University, 6102 Perth, Australia \\ ${ }^{3}$ Duke-NUS Medical School, National University of Singapore, 119077 Singapore, Singapore \\ ${ }^{4}$ Institute for Research in Molecular Medicine (INFORMM), Universiti Sains Malaysia, 11800 USM Penang, Malaysia \\ ${ }^{5}$ Department of Cardiology, Sir Charles Gairdner Hospital, 6009 Perth, Australia \\ ${ }^{6}$ Western Australia Country Health Service, 6000 Perth, Australia \\ *Correspondence: mittalanika92@gmail.com (Anika Mittal) \\ Academic Editors: Christian Hengstenberg and George Dangas \\ Submitted: 5 December 2021 Revised: 9 January 2022 Accepted: 11 January 2022 Published: 9 February 2022
}

\begin{abstract}
Background: Vascular brachytherapy (VBT) used to be an effective treatment modality for management of in-stent stenosis but was superceded by drug eluting stents (DES) which had shown a greater efficacy. However, there is no clear evidence to support superior management for in-stent restenosis (ISR) which continues to be a challenge. Methods: We conducted a systematic review of the literature and appraised PubMed, Medline, Web of science, ProQuest and Cochrane databases from 2000 to 2020. We assessed comparative outcomes including efficacy (as assessed by measuring major adverse cardiac events, target vessel revascularisation, target lesion revascularisation, all-cause mortality, target lesion myocardial infarction and stent thrombosis) and safety of VBT. Results: Of 1083 records obtained, a total of 8 retrospective studies met the inclusion criteria. In the included studies, major adverse cardiac events (MACE) rates ranged from $10 \%$ to $17.5 \%$ in the VBT group compared to $14.1 \%$ to $28.2 \%$ in the re-DES group at one year follow up. There were lower rates of target vessel revascularisation (VBT 10-22.8\%; control 18-22.9\%) and target lesion revascularisation (VBT 10-14.1\%, Control 8-22.1\%) between the VBT and re-DES groups. There were significantly low rates of all-cause mortality (1-5.4\%), target lesion myocardial infarction $(0-7 \%)$ and stent thrombosis $(0-2.1 \%)$ in the VBT group at one year. Conclusions: VBT is considered to be an effective and safe treatment strategy in complex patients with multiple risk factors for DES-ISR in initial reports. There are no long-term comparison studies available beyond 1 year. There is a need for randomised controlled trials to objectively assess the role of VBT compared to DES and drug coated balloons.
\end{abstract}

Keywords: brachytherapy; coronary artery disease; in-stent restenosis; drug eluting stents

\section{Introduction}

Cardiovascular diseases are the leading cause of death globally with 17.9 million deaths each year, an estimated $31 \%$ of all deaths worldwide [1,2]. Of these deaths, $85 \%$ are due to coronary artery disease (CAD) and cerebrovascular disease [3]. Globally, coronary artery disease affects around 126 million individuals which is approximately $1.72 \%$ of the world's population [4]. The pathogenesis of CAD involves the development of atherosclerotic lesions in the coronary arteries [2].

The initial management of CAD included plain old balloon angioplasty (POBA) however there were significant drawbacks to this technique including re-narrowing of the coronary arteries due to acute vessel closure secondary to dissection, elastic recoil, late vascular remodelling and neointimal proliferation [2]. The rate of restenosis ranged from $30-60 \%$ [5]. Elastic recoil occurred in 5-10\% of patients immediately (minutes to hours) after the procedure leading to a rebound occlusion of the artery [2]. This often led to severe complications including acute myocardial infarction and the need for emergency coronary artery bypass grafting (CABG) [2]. To overcome these issues, coronary stents (bare metal stents) were invented which prevented late recoil by scaffolding the balloon-dilated artery and sealing the dissection flaps [2]. However, the medium and long term follow up of bare metal stents (BMS) revealed 30$40 \%$ incidence of in-stent restenosis (ISR) secondary to proliferation and migration of smooth muscle cells within the stents $[2,6]$. To further overcome ISR, drug eluting stents (DES) were introduced. There has been a recent review published by Megaly et al. [7] which examined the outcomes with VBT in recurrent ISR. Megaly et al. [7] included 5 observational studies totalling 917 patients with recurrent ISR (at least 2 episodes). They assessed outcomes such as target vessel revascularisation (TVR) (treated by Percutaneous coronary intervention/PCI or CABG), MI and all-cause mortality. Megaly et al. [7] demonstrated that recurrent ISR is difficult to treat with no consensus on optimal treatment strategy. 


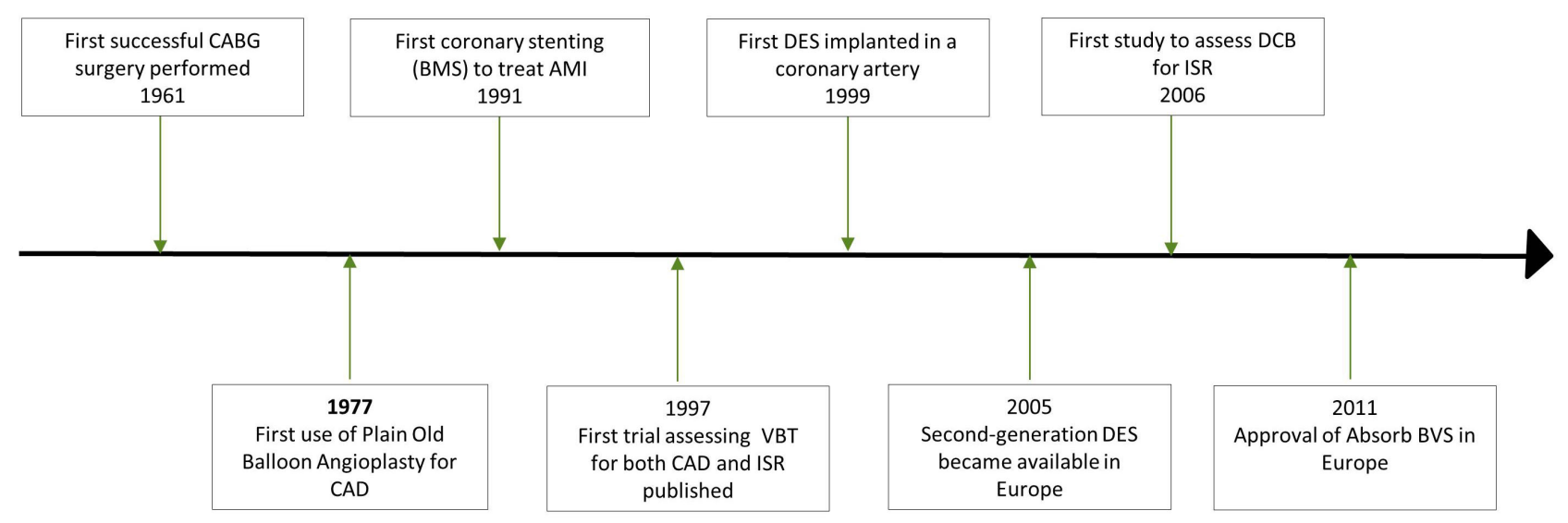

Fig. 1. Timeline of major interventions for coronary artery disease and in-stent restenosis in humans. AMI, acute myocardial infraction; BMS, bare metal stent; BVS, bioresorbable vascular scaffold; CABG, coronary artery bypass grafting; CAD, coronary artery disease; DCB, drug coated balloon; DES, drug eluting stent; ISR, in-stent restenosis; VBT, vascular brachytherapy.

Given the absence of an optimum treatment strategy for this condition, we conducted an in-depth review of the different trials and demonstrated the variabilities in the comparisons of morbidities, methodologies and outcomes concluding the performance of VBT as a safe and effective treatment modality compared to other treatment modalities (including re-DES) among published studies.

\section{Historical perspective}

The timeline of the various major interventions used for CAD and in-stent restenosis (ISR) is illustrated in Fig. 1 $[2,5,8-12]$.

\subsection{Drug eluting stent (DES) restenosis}

DES has emerged to be superior to BMS for coronary artery stenosis and hence have replaced them to a great extent [13-16]. Despite the effectiveness of DES, there are reports of DES in-stent restenosis (DES-ISR) ranging from $3 \%$ to $20 \%$ within 5 years of stent implantation, depending on patient and lesion characteristics and DES type especially in patients with more complex lesions [13,1721]. ISR usually occurs between 3 and 20 months after stent placement and when DES-ISR occurs, it is usually not benign and very difficult to treat $[17,22-24]$. The patients usually present with unstable angina (16-66\%) or myocardial infarction (1-20\%) [25]. Management of DESISR continues to be a challenge [20,23,26,27]. Re-stenting of DES-ISR is associated with higher rates of recurrences and less favourable outcomes for the patients likely due to high-risk features that predisposes them to subsequent ISR $[17,23,24,26]$. This is especially the case when DES is used for smaller arteries, long lesions, complex coronary lesions including diffuse lesions, in patients with diabetes or a history of CABG [15,20,23,28-32]. Other indications include recalcitrant ISR and coronary bifurcation lesions [33-35].
Current research suggests that DES-ISR is mostly focal in nature and therefore easier to treat with likely better clinical outcomes compared to diffuse lesions [13,20,23,28, 29,34]. Cosgrave et al. [29] demonstrated the rate of angiographic restenosis to be $17.8 \%$ in the focal DES-ISR lesion group compared to $51.1 \%$ in the non-focal group (Odds ratio [OR] 5.0, 95\% Confidence interval [CI] 1.1 to $23.0 ; p$ $=0.03)$. The incidence of target lesion revascularisation (TLR) in this study was $9.8 \%$ in the focal group and $23 \%$ in the non-focal group ( $p=0.007)$ [29]. The late lumen loss was lower in the focal group ( 0.46 [Interquartile range (IQR) 0.11 to 0.83 ] compared with 1.08 [IQR 0.14 to 1.8 ]; $p=0.007$ ) [29]. Thus, the pattern of DES-ISR is a predictor for subsequent reintervention $[29,36]$.

Current recommendations for DES-ISR.

Multiple alternatives are available for the treatment of DES-ISR including balloon angioplasty, drug coated balloons (DCB), de novo or repeat BMS implantation, repeated DES implantation using the same or a different DES, Vascular brachytherapy (VBT), CABG and more recently bioresorbable scaffolds [16,18,20,26,37].

BMS are unfortunately associated with a high restenosis rate compared to DES [26]. They have a limited role in the management of DES-ISR in situations where there is a high risk of bleeding secondary to dual antiplatelet therapy [26].

There is Level 1 evidence for the use of DES for treatment of restenosis or re-occlusion if no contraindications exist to extended dual antiplatelet therapy (DAPT) $[16,38,39]$. For this reason, repeat DES implantation for DES-ISR is a common clinical practice $[13,19]$. It has been shown to be safe in randomized clinical trials $[13,40]$. However, with the current recommendation of using re-DES for DES-ISR, there is debate whether to select same or different type of DES [26,41,42]. The reasoning behind switching to a different DES is to overcome drug resistance and 
specific polymer related problems [26]. However, switching of DES to a different type of DES has not been shown to be beneficial in clinical trials $[20,26]$. There seems to be high restenosis recurrence rates post DES implantation for DES-ISR regardless of the use of same or different DES $[13,18,19,26]$.

Implantation of multiple stent layers in the coronary vessels comes with higher local concentrations of antirestenotic drugs, greater impairment of normal vasomotion and increased inflammatory stimuli [13]. Overlying multiple stents have been found to be suboptimal with high residual stenosis rates despite high inflation pressures in some patients [19]. This can be attributed to the underexpansion of the stents which further predisposes to ISR and prove to be a challenge for further intervention [19,20,25]. For this reason, interest has shifted to DCB that can deliver effective neointimal suppression without implanting another stent layer $[13,14]$. There is evidence to suggest that DCBs require a shorter course of DAPT ( $\sim 1$ month) compared to DES [43-45]. A meta-analysis by Siontis et al. [14] demonstrated everolimus eluting stent (DES) to deliver best angiographic and clinical outcomes followed by drug coated balloons. Some randomised trials have shown DCB to deliver comparable results to DES [13,39]. However, a recent RIBS-IV trial investigating intra- stent restenosis of drug eluting stents: paclitaxel-eluting balloon vs everolimus eluting stent (EES) trial compared second generation everolimus eluting DES to DCB for DES-ISR [20]. It showed better angiographic and clinical outcomes with DES over DCB (minimal lumen diameter: $2.03 \mathrm{~mm}$ vs $1.80 \mathrm{~mm}, p<0.01$; Major adverse cardiac events (MACE) $10 \%$ vs $18 \%, p=0.04$ ) [20]. This could be due to the limited exposure time during balloon inflation to have a potent anti-proliferative effect [14]. Moreover, DCB are unable to prevent the almost immediate elastic recoil phenomenon and further includes risk of occlusive dissection requiring bailout stenting $[23,45]$.

There is a concern that patients with DES-ISR should be maintained on DAPT until a complication occurs due to the high likelihood of recurrence of ISR in these patients [23]. In addition, there has been a suggestion to consider patients who either have contraindications or show noncompliance to long term DAPT for coronary artery bypass grafting (CABG) [23]. CABG provides almost complete revascularisation and hence has better survival and quality of life $[46,47]$. It has a role in patients with recurrent episodes of diffuse ISR in large vessels, left anterior descending/left main coronary artery lesions and in patients with multivessel disease $[39,47]$. Certain other characteristics such as being diabetic, having left ventricular dysfunction (Ejection fraction $<35 \%$ ), having anatomy resulting in incomplete revascularisation with PCI or having severely calcified coronary artery lesions limiting lesion expansion with PCI favours CABG over re-DES [39]. Currently however, $\mathrm{CABG}$ is considered to be the last option for manage- ment of ISR considering it is an invasive procedure with potential intra- and post-operative complications including cerebrovascular accident, atrial fibrillation, nosocomial infections which can subsequently lead to death [9,23,47].

Ariyaratne et al. [48] assessed the cost effectiveness of percutaneous coronary intervention compared to surgery for multivessel coronary artery disease. They preferred CABG over re-DES to be the cost-effective treatment modality in the long run (over 10 years or lifetime) [48]. Re-DES has higher index procedure costs compared to $\mathrm{CABG}$ due to cost of stents and other consumable devices [49]. At short term ( $\sim 1$ year), re-DES is economically superior to CABG across various studies [48]. CABG likely offers survival advantage in the long run however requires longer recovery period and need for intensive rehabilitation post-surgery [48]. Due to this, the costs associated with post procedure hospital stay and physician costs are significantly higher in the CABG group [49]. For left main coronary artery lesions, re-DES is superior to CABG [48]. Results from the freedom trial demonstrated higher life expectancy and quality adjusted life expectancy in the CABG group compared to the re-DES group at 5 year follow up [49]. Re-DES is still preferred strategy for patients with less complex disease due to clinical and economic reasons [50]. Similarly, DCB is a cost-effective treatment strategy in the long run despite the high initial costs [51].

Due to the above issues, there has been recent interest in the use of bioresorbable scaffolds for the treatment of ISR as they dissolve over a period of time ( $\sim 3-4$ years) not leaving a trigger for restenosis [24,52]. However, this is still in early stages of development with some initial trials not showing any advantages of bioresorbable scaffolds over DES with associated small but significant rates of stent thrombosis [24,53]. A recent meta-analysis by Chen et al. [54] further demonstrated that bioresorbable scaffolds have higher risk of target lesion failure, stent thrombosis and cardiac death than DES.

\subsection{Vascular brachytherapy}

Historically VBT was used with some degree of success reducing re-stenosis however; this was limited by the availability of equipment and the expertise of the user [20,23,33,37,55,56]. Fig. 2 summarizes some of the advantages (in red) and disadvantages (in blue) of each of VBT, DCB, CABG and re-DES for complex DES-ISR.

VBT was the first effective antiproliferative treatment for ISR [57]. It delivers radiation to the areas of in-stent stenosis thereby inhibiting neointimal formation within the stent and exerting anti-inflammatory effects $[17,35,58]$. Both beta radiation and gamma radiation have been used effectively to treat coronary ISR [59-61]. At one stage, it's use was widespread, and it was available across hundreds of centres across US [57] however, currently its use is very limited [20,23]. Contributing factors include the improved clinical outcomes with re-DES, necessity for spe- 


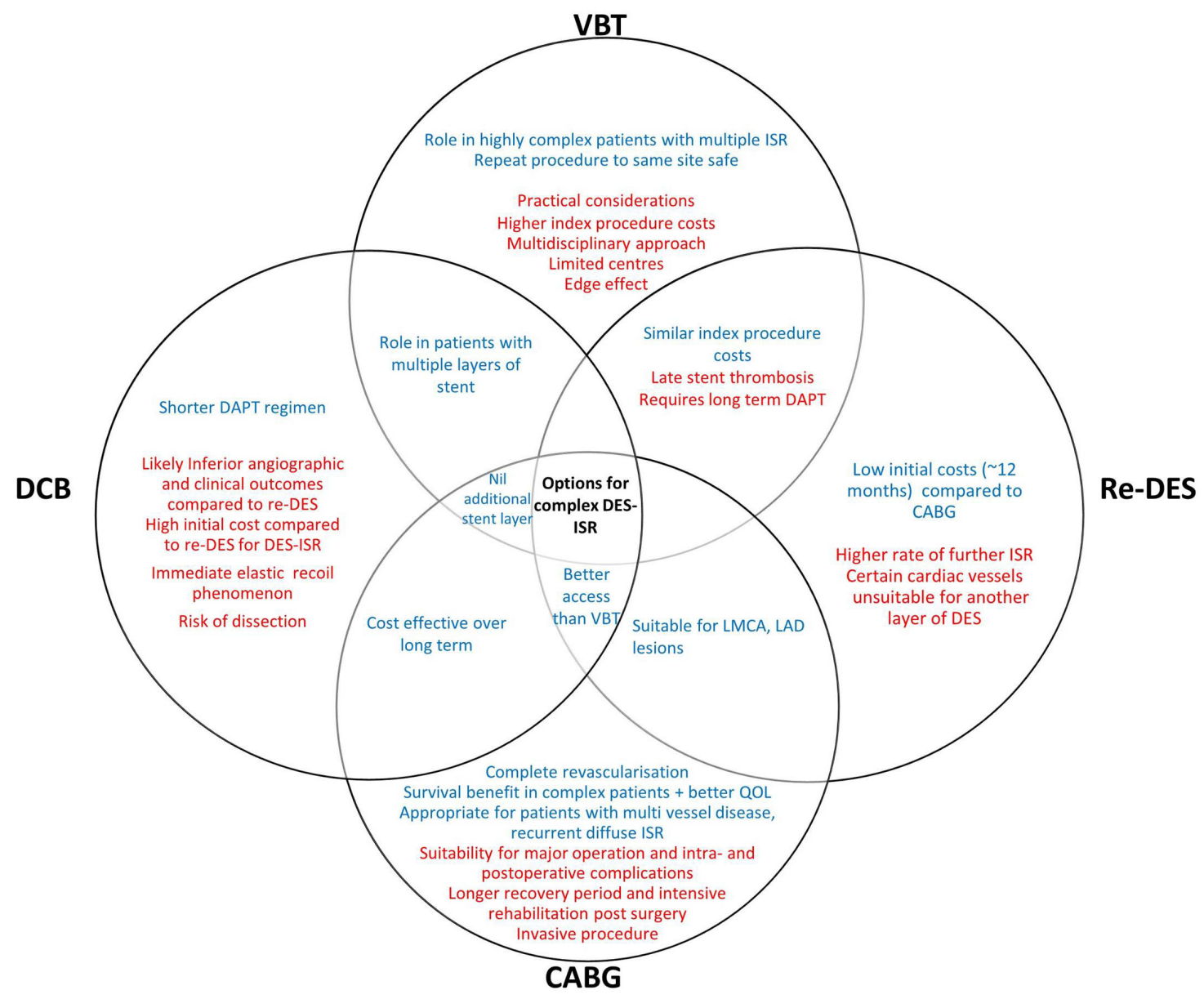

Fig. 2. Venn diagram demonstrating the advantages (blue) and disadvantages (red) of each of VBT, DCB, CABG and re-DES for DES-ISR. CABG, coronary artery bypass grafting; DAPT, dual antiplatelet therapy; DCB, drug coated balloon; DES, drug eluting stent; ISR, in-stent restenosis; LAD, left anterior descending; LMCA, left main coronary artery; QOL, quality of life; VBT, vascular brachytherapy.

cialized equipment, subspecialty expertise, complexity of the VBT procedure, issues with radioprotection/radiation dosing and the lack of uptake outside of expert centres $[13,20,23,28,55,62,63]$. There are limited centres available to deliver VBT with a further limitation of availability of staff with licences to deliver the treatment [62].

Patients with ISR present with acute coronary syndromes (ACS) that require urgent revascularization [64]. To deliver brachytherapy in such scenarios, a team comprising of an interventional cardiologist, radiation oncologist and radiation physicist is required at a short notice which can prove logistically challenging [64].

Some of the practical considerations that hinder widespread availability and use of VBT are dosimetry, shielding, handling and disposal of the radioactive source, operator certifications and regulatory approval [63]. A number of radioisotopes have been used effectively in the past at a range of doses for treating coronary artery disease and ISR as highlighted in the studies included in this review. Certain radioisotopes require medical personnel to leave the room during treatment however certain particles including beta particles has minimal radiation concerns regarding whole body exposure and only requires precautions during handling of these sources especially to the fingers and hands [63]. Once the procedure is completed, it is essential to check the patient, the equipment and the laboratory for any potential contamination. It is further essential to secure the radioactive source in a special shielded container [63]. Delivery of radiation therapy for ISR requires a multidisciplinary approach with only the radiation oncologist being able to prescribe radiation therapy. Hence, the ability to deliver radiation therapy requires specific training and certification for the cardiology team.

Furthermore, there is a role for repeat VBT and stenting post VBT if required. Repeat VBT to the site of stent stenosis has been found to be effective and safe if spaced 12 months from the initial therapy [17,33]. Zahn et al. [65] have demonstrated that coronary stenting with sirolimuseluting stents in patients with restenosis after VBT is safe and effective [66]. 
Due to limited use of VBT for DES-ISR currently, there is lack of available data comparing cost effectiveness of VBT compared to re-DES for DES-ISR. A study by Reynolds et al. [67] comparing Sirolimus eluting stent (SES) to brachytherapy for ISR demonstrated that SES to be economically superior to VBT over a period of 1 year due to reduced rate of repeat TVR, any repeat revascularisation, reduced need for $\mathrm{CABG}$ and a trend towards a lower cardiac rehospitalisation rate. The DES (SES) group was associated with higher initial device costs however this was offset by higher physician fees associated in the brachytherapy group such that the total cost for the index procedure and hospitalisation were similar in the two groups [67]. This was mainly due to the need for presence of a radiation oncologist during the procedure [67].

Edge effect in Vascular Brachytherapy.

There have been concerns about the edge effect and late recurrences of stenosis with radiation therapy for ISR [33,35,58,68]. Krotz et al. [58] have described edge effect as a phenomenon of excessive neointimal proliferation at the edges of an irradiated segment which is likely due to axial dose fall off and/or barotrauma by the angioplasty procedure. Thus, edge effect can be significantly reduced by using appropriate radiation source length to avoid geographic miss, the disparity of the effective axial radiation length and the length of the vessel segment having been injured by the angioplasty procedure [58].

Late stent thrombosis.

The issue of late stent thrombosis exists for both DES and VBT [15,23,25,69-71]. The pathophysiology of late thrombosis in DES has been attributed to delayed arterial healing characterized by persistent fibrin deposition and incomplete endothelialisation around stent struts as long as 4 years after the intervention [30]. DES thrombosis has been associated with renal insufficiency, diabetes, long total stent length, bifurcation stenting, incomplete stent expansion, poor stent apposition, stent strut penetration into a necrotic plaque core, left ventricular dysfunction, stent implantation during ACS and treatment of diffuse ISR [30]. Late recurrence of stenosis usually happens 6 months to 1year post VBT [15]. There have been some reports to suggest that extending the use of DAPT to 6 to 12 months after irradiation can significantly reduce the rate of late thrombosis $[35,58,72]$.

\section{Methodology for systematic review}

PubMed, Medline, Web of science, Proquest and Cochrane database were systematically searched for studies that assess the efficacy of VBT for DES-ISR. The following medical subject heading terms were included: (coronary brachytherapy or vascular brachytherapy) and (DES restenosis or drug eluting stent restenosis). The reference lists of all included studies were manually searched. The search was conducted for studies published since the year 2000. Fig. 3 summarizes the search selection process.
Case reports $[73,74]$ and initial clinical experience [75] were not included in this review. The study by Kim et al. [76] was excluded as there were no results available for the brachytherapy group for DES restenosis. The authors reported results for conventional treatment for DES restenosis which included both lesions treated with cutting balloon and lesions treated with brachytherapy [76]. The study by Moussa et al. [77] and Mishkel et al. [78] were excluded due to lack of data as there was only one patient who received VBT for DES restenosis in both studies. The study by Ohri et al. [79] assessed the safety of VBT in patients with DES restenosis only. The study by Buchanan et al. [24] was excluded as it requires further analysis of data which was not available to determine the effectiveness of VBT for DES restenosis. The study by Chen et al. [21] was excluded as it did not specify whether the last stent layer was BMS or DES. Megaly et al. published two studies in 2020 [80,81]. Their study which further characterized the data to determine effects of atherectomy combined with VBT was excluded [81]. There were no studies identified that directly compare VBT to DCB.

\section{Results}

\subsection{Patient demographic and baseline clinical characteristics}

All eligible studies are retrospective in nature. The patients in this study either had VBT for DES-ISR initially or presented with symptoms including angina requiring VBT (Table 1, Ref. [18,22,35,80,82-85]). The patients presenting with ST segment elevation myocardial infarction (STEMI), cardiogenic shock or angiographic stent thrombosis were excluded from some of the studies (Table 1). The baseline clinical characteristics of the patients in the individual studies are summarized in Table 2 (Ref. [18,22,35,80,82-85] Majority of the patients had cardiac risk factors including age $>65$, male gender, hypertension, hyperlipidaemia and high body mass index (BMI) (Table 2). A significant proportion of patients had risk factors including diabetes, prior CABG and current smoking.

\subsection{Lesion characteristics and type of radiation}

The lesion characteristics and radiation therapy used in each of the studies are summarized in Table 3. Most of the patients had focal lesion on angiography in the study by Negi et al, and Torguson et al. [84,85]. The strontium/Yttrium 90 beta source was used across all studies with some utilization of the phosphorus-32 beta source and iridium-192 beta source (Table 3, Ref. [18,22,35,80,8285]).

\subsection{Efficacy}

\subsubsection{Major adverse cardiac events (MACE)}

Multiple studies have demonstrated lower rates of MACE with VBT compared to re-DES for DES-ISR (Table 4, Ref. [18,22,35,80,82-86], Supplementary Table 1), 


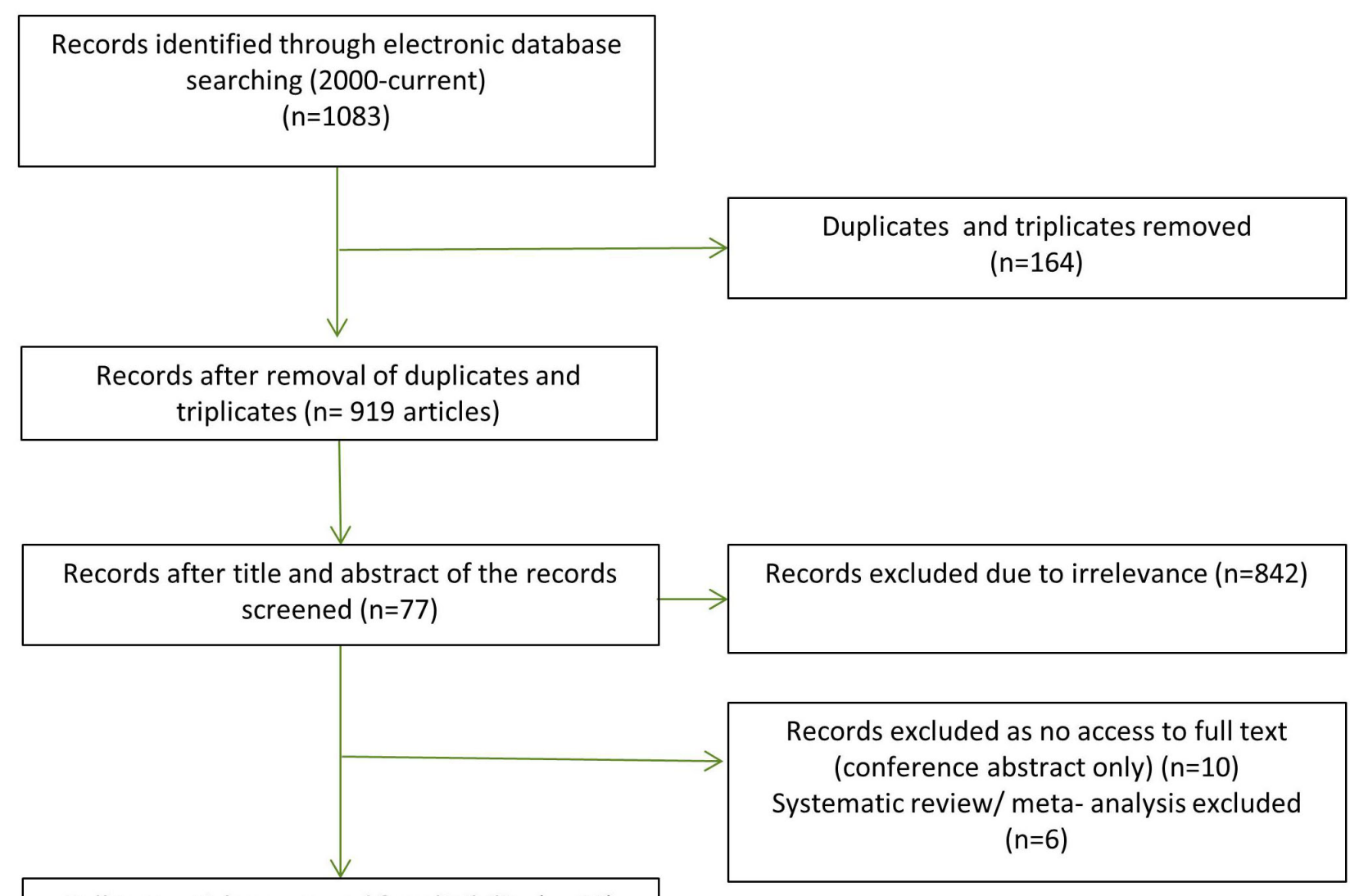

Full text articles assessed for eligibility $(n=61)$

Studies with last layer bare metal stent excluded $(n=45)$

Certain studies which met the inclusion criteria were excluded due to lack of available data $(n=8)$

Fig. 3. Flowchart describing search and study selection process. This search strategy identified 1083 records which were screened (removing duplicates, triplicates, irrelevant articles, articles with last layer bare metal stent, articles with no access to full text) and 8 studies were identified for inclusion.

however, due to the paucity of data one study showed lower rates of MACE with VBT while another study showed lower rates of MACE with re-DES. MACE rates ranged from $10 \%$ to $17.5 \%$ in the VBT group when compared to re-DES group where it ranged from $14.1 \%$ to $28.2 \%$ at one year follow up. In studies with no comparison group, the MACE rates ranged from $16.8 \%$ to $26 \%$ at 1 year (Table 4 ). Further follow up at 3 years revealed MACE rates of 31.9 (TLR MACE in the study by Negi et al. [84]) to $34.3 \%$ in the study by Megaly et al. [80].

Varghese et al. [35] demonstrated VBT to be superior to the non-VBT group for multilayered DES-ISR. They found significantly lower MACE in the VBT group (13.2\%) compared to the non-VBT group (28.2\%) at one year follow up $(p=0.01)$ [35]. Thus, VBT has been shown to be a feasible option for patients with multilayered DES-ISR.

Maluenda et al. [22] also compared VBT with balloon angioplasty for DES-ISR and the results were comparable between the two groups at one year with MACE of $17.5 \%$ in the VBT group, $14.1 \%$ in the re-DES group and $18 \%$ in the balloon angioplasty group $(p=0.57)$.

\subsubsection{Target vessel revascularization (TVR)}

There were comparable rates of TVR between the VBT and re-DES groups in the study by Maluenda et al. [22] $(22.8 \%$ in the VBT group, $19.5 \%$ in the re-DES group, $19.6 \%$ in the balloon angioplasty group; $p=0.79$ ) at one year. The TVR rates ranged from $10 \%$ to $24 \%$ in the VBT 
Table 1. Inclusion criteria, exclusion criteria and the type of DES for the studies included.

\begin{tabular}{|c|c|c|c|}
\hline Clinical Study (year) & Inclusion criteria & Exclusion criteria & First or second-generation DES \\
\hline Megaly et al. (2020) [80] & $\begin{array}{l}\text { Patients undergoing VBT for DES-ISR between January } 2014 \\
\text { and September } 2018 \text { at Minneapolis Heart Institute at Abbott } \\
\text { Northwestern Hospital. }\end{array}$ & $\begin{array}{l}\text { Patient with DES-ISR lesion treated with } \\
\text { brachytherapy in the past. }\end{array}$ & Mostly second-generation DES. \\
\hline Meraj et al. (2019) [83] & $\begin{array}{l}\text { Patients undergoing VBT for DES-ISR who presented with ACS } \\
\text { or chronic stable angina and were found to have ISR on quantita- } \\
\text { tive coronary stenosis assessment (QSA) between January } 2011 \\
\text { and Oct } 2016 \text { at Northwell. }\end{array}$ & & Not specified. \\
\hline Varghese et al. (2018) [35] & $\begin{array}{l}\text { Patients with angina symptoms or ischemia on non-invasive } \\
\text { tests undergoing PCI for recurrent DES restenosis with at least } \\
2 \text { layers of stents with last layer being DES between 2011-2015 } \\
\text { at Mount Sinai Hospital, New York. }\end{array}$ & $\begin{array}{l}\text { Patients presenting with cardiogenic shock or } \\
\text { stent thrombosis. }\end{array}$ & $\begin{array}{l}\text { First generation DES in } 14 \% \text {, second } \\
\text { generation DES in } 86 \% \text {. }\end{array}$ \\
\hline Mangione et al. (2017) [82] & $\begin{array}{l}\text { Patients undergoing VBT for resistant DES-ISR between } \\
\text { September } 2009 \text { to March } 2015 \text { at the Brigham and Women's } \\
\text { Hospital. }\end{array}$ & & $\begin{array}{l}\text { First generation DES in } 5 \% \text { and second } \\
\text { generation DES in } 19 \% \text {. Both in } 16 \% \text {; } \\
\text { unknown in } 60 \% \text {. }\end{array}$ \\
\hline Negi et al. (2016) [84] & $\begin{array}{l}\text { Patients with angina and angiographic evidence of DES-ISR un- } \\
\text { dergoing VBT between } 2004 \text { and } 2012 \text { selected from an ongoing } \\
\text { clinical PCI registry at Medstar Washington hospital centre. }\end{array}$ & $\begin{array}{l}\text { Patients presenting with STEMI, cardiogenic } \\
\text { shock, angiographic evidence of stent thrombo- } \\
\text { sis or with fewer than } 3 \text { years of follow up. }\end{array}$ & $\begin{array}{l}\text { First generation DES in } 64 \% \text { and second } \\
\text { generation DES in } 36 \% \text { of patients. }\end{array}$ \\
\hline Maluenda et al. (2012) [22] & $\begin{array}{l}\text { Patients presenting with recurrent symptoms of ischemia and an- } \\
\text { giographic ISR after DES implantation between May } 2003 \text { and } \\
\text { September } 2008 \text { at Washington hospital centre. }\end{array}$ & $\begin{array}{l}\text { Patients presenting with STEMI, cardiogenic } \\
\text { shock or angiographic evidence of stent throm- } \\
\text { bosis. }\end{array}$ & First generation DES (PES/SES). \\
\hline Bonello et al. (2008) [18] & $\begin{array}{l}\text { Patients presenting with ischemia/stable or unstable angina (re- } \\
\text { lated to the restenotic lesion) and undergoing VBT for DES-ISR } \\
\text { with completion of at least } 12 \text { months follow up between April } \\
2003 \text { and June } 2006 \text { at Washington Hospital centre. }\end{array}$ & $\begin{array}{l}\text { Patients presenting with STEMI, cardiogenic } \\
\text { shock or angiographic evidence of stent throm- } \\
\text { bosis. }\end{array}$ & First generation DES (PES/SES). \\
\hline Torguson et al. (2006) [85] & $\begin{array}{l}\text { Patients presenting with stable/unstable angina with documenta- } \\
\text { tion of ischemia and angiographic evidence of restenotic lesion } \\
\text { within } 1 \text { or more DES since } 2002 \text { to } 8 \text { independent centres. } \\
\text { The control group included patients who met the above inclu- } \\
\text { sion/exclusion criteria and underwent PCI with DES implanta- } \\
\text { tion at Washington Hospital centre. }\end{array}$ & $\begin{array}{l}\text { Patients presenting with STEMI, cardiogenic } \\
\text { shock or angiographic evidence of stent } \\
\text { thrombosis or patients who were unable to take } \\
\text { long term antiplatelet therapy. }\end{array}$ & First generation DES. \\
\hline
\end{tabular}

ACS, Acute coronary syndrome; BA, Balloon Angioplasty; DES, Drug eluting stent; ISR, in-stent restenosis; IVUS, Intravascular ultrasound; PES, Paclitaxel eluting stent; PCI, Percutaneous coronary intervention; SES, Sirolimus eluting stent; STEMI, ST segment elevation myocardial infarction; VBT, Vascular brachytherapy. 
Table 2. Clinical characteristics of patients involved in the individual studies.

\begin{tabular}{|c|c|c|c|c|c|c|c|c|}
\hline Clinical Study & Megaly et al. [80] & Meraj et al. [83] & Varghese et al. [35] & Mangione et al. [82] & Negi et al. [84] & Maluenda et al. [22] & Bonello et al. [18] ' & Torguson et al. [85] \\
\hline Age (years) & $65.7 \pm 11.6$ & $66.6 \pm 10.7$ & $65 \pm 11$ & $66 \pm 12$ & $65 \pm 11$ & $63.7 \pm 11.4$ & $63 \pm 12$ & $61.6 \pm 13.5$ \\
\hline $\operatorname{BMI}\left(\mathrm{Kg} / \mathrm{m}^{2}\right)$ & - & $29.6 \pm 5.5$ & $\begin{array}{c}29.2 \pm 5.3 \text { in VBT arm } \\
\text { and } 29.8 \pm 5.9 \text { in control arm }\end{array}$ & - & $30.1 \pm 6.2$ & $29.9 \pm 6.5$ & $29.9 \pm 6.1$ & - \\
\hline Male (\%) & $99(69 \%)$ & $192(66 \%)$ & $248(75 \%)$ & $68(67 \%)$ & $115(62 \%)$ & $350(62 \%)$ & $59(59 \%)$ & $71(64 \%)$ \\
\hline Smokers (\%) & - & $18(6.2 \%)$ & $46(14 \%)$ & $53(53 \%)$ & $115(62 \%)$ & $104(18.5 \%)$ & $12(13.3 \%)$ & $64(58 \%)$ \\
\hline Hypertension & - & $282(97.2 \%)$ & $325(99 \%)$ & $98(98 \%)$ & $177(95 \%)$ & $526(93.4 \%)$ & $90(90.9 \%)$ & $85(77 \%)$ \\
\hline Dyslipidaemia & $142(99.3 \%)$ & $273(94.1 \%)$ & $324(98.7 \%)$ & $101(100 \%)$ & $175(94 \%)$ & $533(95 \%)$ & $92(92.9 \%)$ & $92(83 \%)$ \\
\hline Prior CABG & $77(54 \%)$ & $138(47.6 \%)$ & $133(40.5 \%)$ & $48(48 \%)$ & $102(55 \%)$ & $219(39.2 \%)$ & $55(56.7 \%)$ & $39(35 \%)$ \\
\hline
\end{tabular}

BMI, Body Mass Index; VBT, Vascular brachytherapy; CABG, Coronary artery bypass grafting. 
Table 3. Lesion characteristics and type of radiation for patients undergoing VBT.

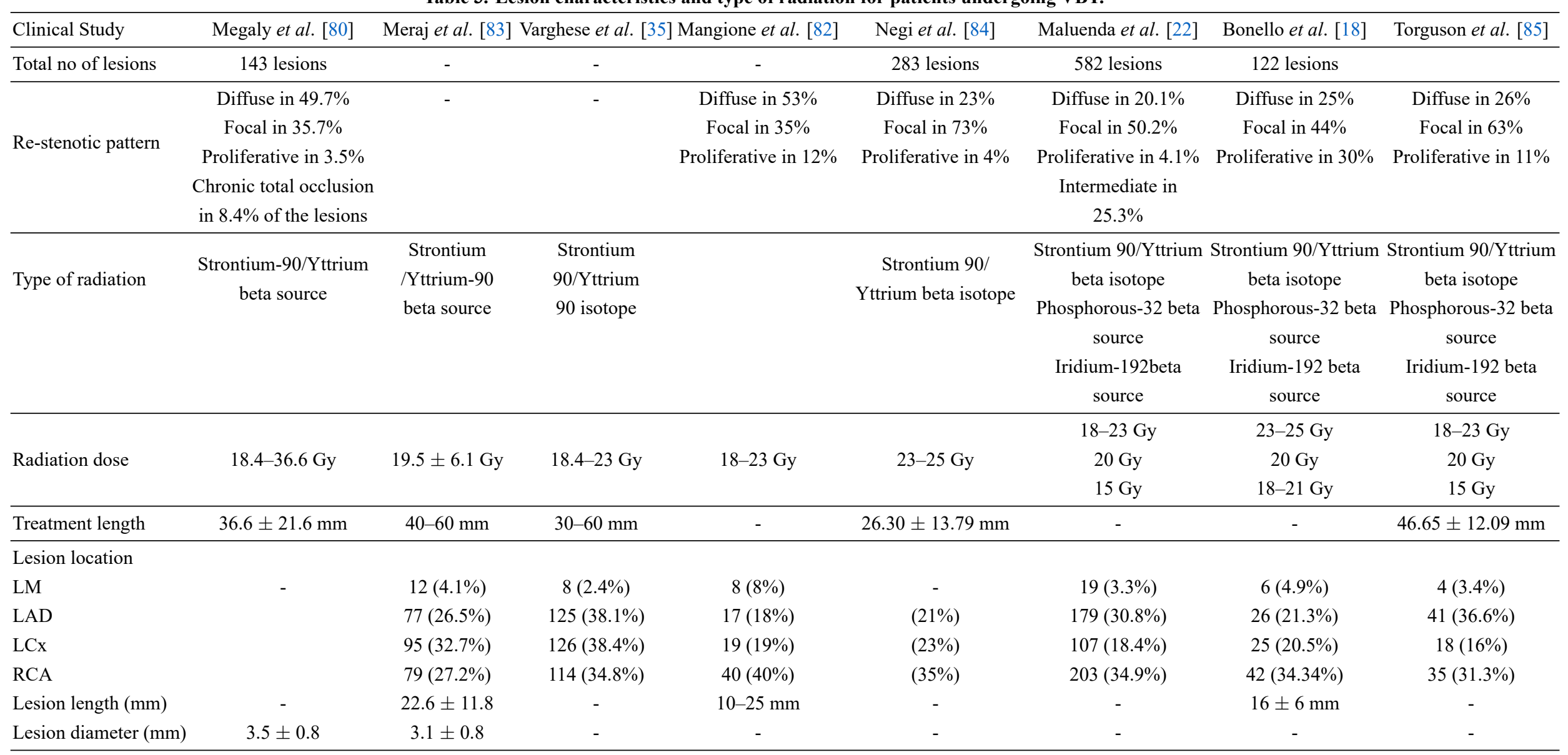

LAD, Left anterior descending; LCx, Left circumflex; LM, Left main artery; RCA, Right coronary artery; VBT, Vascular brachytherapy. 
Table 4. Clinical outcomes of patients undergoing VBT for DES-ISR.

\begin{tabular}{|c|c|c|c|c|c|c|c|c|}
\hline Clinical study & $\begin{array}{l}\text { Megaly et al. } \\
(2020) \text { [80] }\end{array}$ & $\begin{array}{l}\text { Meraj et al. } \\
\text { (2019) [83] }\end{array}$ & $\begin{array}{l}\text { Varghese et al. } \\
\text { (2018) [35] }\end{array}$ & $\begin{array}{l}\text { Mangione et al. } \\
\text { (2017) [82] }\end{array}$ & $\begin{array}{l}\text { Negi et al. } \\
(2016)[84]\end{array}$ & $\begin{array}{l}\text { Maluenda et al. } \\
\text { (2012) [22] }\end{array}$ & $\begin{array}{c}\text { Bonello et al. (2008) } \\
{[18]}\end{array}$ & Torguson et al. (2006) [85] \\
\hline Comparison group & Nil & Nil & Non-VBT ${ }^{a}$ & Nil & Nil & $\begin{array}{c}\text { Re-DES } \\
\text { Balloon } \\
\text { Angioplasty }\end{array}$ & Nil & Re-DES \\
\hline Total number of patients & 116 & 290 & 328 & 101 & 186 & 563 & 99 & 111 \\
\hline VBT & 116 & 290 & 197 & 101 & 186 & 132 & 99 & 61 \\
\hline Control arm & NA & NA & 131 & NA & NA & $\begin{array}{l}327 \text { (re-DES) } \\
104 \text { (balloon } \\
\text { angioplasty) }\end{array}$ & 0 & 50 \\
\hline Follow up time & $\begin{array}{l}\text { Median follow up } \\
\text { of } 24.7 \text { months } \\
\text { Maximum follow } \\
\text { up } 63 \text { months }\end{array}$ & 24 months & 1 year & 3 years & 3 years & 1 year & 1 year & 8 months \\
\hline Length of DAPT & Indefinite & Indefinite & $\begin{array}{c}1 \text { year in DES arm } \\
\text { and } 3 \text { years in VBT } \\
\text { arm }\end{array}$ & Indefinite & $\begin{array}{l}\text { Minimum of } 12 \\
\text { months }\end{array}$ & $\begin{array}{l}\text { Minimum of } 12 \\
\text { months }\end{array}$ & $\begin{array}{c}\text { Indefinite aspirin and at } \\
\text { least } 12 \text { months of } \\
\text { clopidogrel }\end{array}$ & $\begin{array}{l}\text { Indefinite aspirin with at least } 6 \\
\text { months of clopidogrel in the } \\
\text { re-DES group and at least } 12 \\
\text { months in the VBT group }\end{array}$ \\
\hline Immediate success of VBT & $100 \%$ & - & $100 \%$ & $98 \%$ & $100 \%$ & $99.8 \%$ & $100 \%$ & Not specified \\
\hline \multicolumn{9}{|l|}{$\mathrm{MACE}^{b}$} \\
\hline VBT (1 year) & $20.1 \%$ & - & $13.2 \%$ & - & $16.8 \%$ & $17.5 \%$ & $26 \%$ & $10 \%$ \\
\hline Control (1 year) & - & - & $28.2 \%$ & - & - & $\begin{array}{c}14.1 \% \text { (re-DES) } \\
18 \% \text { (balloon } \\
\text { angioplasty) }\end{array}$ & - & $24 \%$ \\
\hline \multicolumn{9}{|l|}{ TVR } \\
\hline VBT (1 year) & - & - & $15.2 \%$ & $24 \%$ & $19.1 \%$ & $22.8 \%$ & $22 \%$ & $10 \%$ \\
\hline Control (1 year) & - & - & $22.9 \%$ & - & - & $\begin{array}{c}19.5 \% \text { (re-DES) } \\
19.6 \% \text { (balloon } \\
\text { angioplasty) }\end{array}$ & - & $18 \%$ \\
\hline \multicolumn{9}{|l|}{ TLR } \\
\hline VBT (1 year) & $18.9 \%$ & $12.4 \%$ & $10.7 \%$ & - & $12.1 \%$ & $14.1 \%$ & $10 \%$ & $10 \%$ \\
\hline Control (1 year) & - & - & $22.1 \%$ & - & - & $\begin{array}{c}10.3 \% \text { (Re-DES) } \\
14.6 \% \text { (balloon } \\
\text { angioplasty) }\end{array}$ & - & $8 \%$ \\
\hline
\end{tabular}


Table 4. Continued.

\begin{tabular}{|c|c|c|c|c|c|c|c|c|}
\hline Clinical study & $\begin{array}{c}\text { Megaly et al. } \\
(2020)[80]\end{array}$ & $\begin{array}{l}\text { Meraj et al. } \\
\text { (2019) [83] }\end{array}$ & $\begin{array}{c}\text { Varghese et al. } \\
\text { (2018) [35] }\end{array}$ & $\begin{array}{l}\text { Mangione et al. } \\
\text { (2017) [82] }\end{array}$ & $\begin{array}{l}\text { Negi et al. } \\
\text { (2016) [84] }\end{array}$ & $\begin{array}{l}\text { Maluenda et al. } \\
\text { (2012) [22] }\end{array}$ & $\begin{array}{c}\text { Bonello et al. (2008) } \\
\text { [18] }\end{array}$ & Torguson et al. (2006) [85] \\
\hline \multicolumn{9}{|l|}{ All- cause mortality } \\
\hline VBT (1 year) & - & $1.7 \%$ & $1 \%$ & - & $5.4 \%$ & $4.3 \%$ & $4 \%$ & $2 \%$ \\
\hline Control (1 year) & - & - & $4.6 \%$ & - & - & $\begin{array}{c}3.8 \% \text { (Re-DES) } \\
3.5 \% \text { (balloon } \\
\text { angioplasty) }\end{array}$ & - & $4 \%$ \\
\hline \multicolumn{9}{|l|}{ Target lesion $\mathrm{MI}^{c}$} \\
\hline VBT (1 year) & $5.6 \%$ & $3.4 \%$ & $3 \%$ & $0 \%$ & $1.5 \%$ & $2.7 \%$ & $7 \%$ & $2 \%$ \\
\hline Control (1 year) & - & - & $6.9 \%$ & - & - & $\begin{array}{c}2.5 \% \text { (Re-DES) } \\
2.3 \% \text { (balloon } \\
\text { angioplasty) }\end{array}$ & - & $2 \%$ \\
\hline \multicolumn{9}{|l|}{ Stent thrombosis } \\
\hline VBT (1 year) & $2.1 \%$ & - & $1 \%$ & $1 \%$ & $0.5 \%$ & $0 \%$ & $2 \%$ & $0 \%$ \\
\hline Control (1 year) & - & - & $1.5 \%$ & - & - & $\begin{array}{c}1.2 \%(\text { Re-DES) } \\
0 \% \text { (balloon } \\
\text { angioplasty) }\end{array}$ & - & $0 \%$ \\
\hline
\end{tabular}

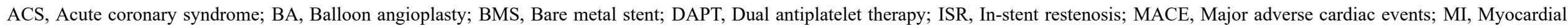
Infarction; Re-DES, Repeat DES; TLR, Target lesion revascularisation; TVR, Target vessel revascularisation; VBT, Vascular brachytherapy.

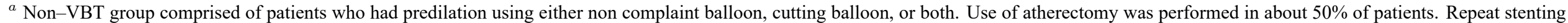
with a DES was performed in a subset of patients.

${ }^{b}$ MACE-

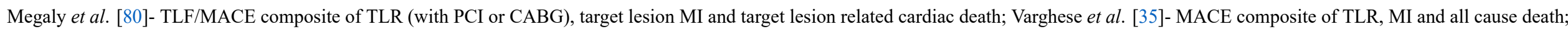

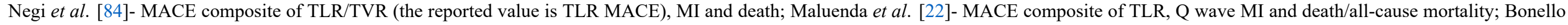
et al. [18]- MACE composite of TVR, MI and death; Torguson et al. [85]- MACE defined as TVR, Q wave MI and death.

${ }^{c}$ MI-

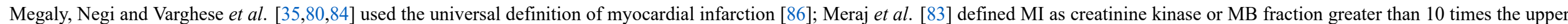

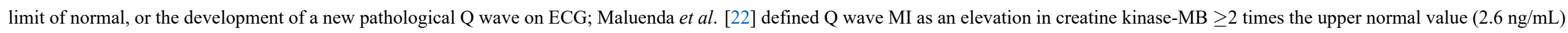

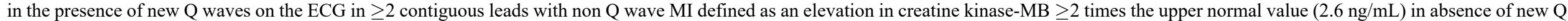

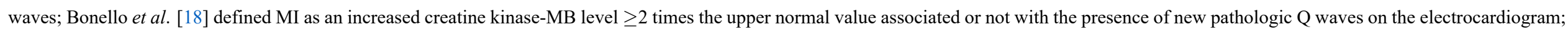

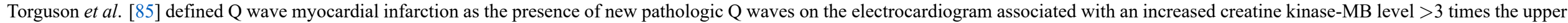
normal value. Non-Q wave myocardial infarction was defined as an increased creatine kinase-MB level $>3$ times the upper normal value without new $Q$ waves. 
group at one year (Table 4). There was an increased proportion of TVR in the non-VBT/DES group (ranging from 18$22.9 \%$ ) compared to the VBT group (10-22.8\%) as highlighted in Table 4. Mangione et al. [82] demonstrated an increase in TVR in the VBT group from $24 \%$ at one year to $42 \%$ at 3 years however there is no comparison group available for this study.

\subsubsection{Target lesion revascularisation (TLR)}

In the studies by Maluenda et al. and Torguson et al., there were comparable TLR rates of $14.1 \%$ and $10 \%$ at one year compared to $10.3 \%(p=0.41)$ and $8 \%(p=1.0)$ in the re-DES group [22,85]. Varghese et al. [35] demonstrated TLR of $10.7 \%$ in the VBT group compared to $22.1 \%$ in the non-VBT group at one year $(p=0.07)$. There was increase in TLR in the VBT group from $18.9 \%$ at one year to $30.8 \%$ at 3 years in the study by Megaly et al. [80] and increase from $12.1 \%$ at one year to $19.4 \%$ at 3 years in the study by Negi et al. [84] however there are no comparison groups in these studies.

\subsubsection{All-cause mortality}

In the studies that compared VBT to re-DES/other modalities, all-cause mortality ranged from $1 \%$ to $4.3 \%$ in the VBT group at one year compared to $3.5 \%$ to $4.6 \%$ in the re-DES/non-VBT group (Table 4). Overall all-cause mortality ranged from $1 \%$ to $5.4 \%$ in the VBT group at one year (Table 4).

There was an increase in the all-cause mortality in the VBT group from $1.7 \%$ at one year to $2.1 \%$ at 2 years in the study by Meraj et al. [83]. Similarly, there was an increase in all-cause mortality from $5.4 \%$ in the VBT group at one year to $13.2 \%$ at 3 years in the study by Negi et al. [84].

\subsubsection{Target lesion MI}

Target lesion MI rates ranged from 0 to $7 \%$ in the VBT group compared to 2 to $6.9 \%$ in the re-DES group (Table 4 ). In the study by Varghese et al. [35], there was higher rates of target lesion $\mathrm{MI}$ in the non-VBT group compared to the VBT group at one year (6.9\% in the re-DES group, $3 \%$ in the VBT group; $p=0.13)$. There was an increase in the rate of target lesion MI over a period of one year to three years across all studies that followed patients for that duration and ranged from $6 \%$ to $10.5 \%$ in the VBT group [80,82-84].

\subsubsection{Stent thrombosis}

There are significantly lower rates of stent thrombosis between the VBT and control groups (Table 4). The stent thrombosis rates ranged $0-2.1 \%$ in the VBT group compared to $0-1.5 \%$ in the non-VBT/re-DES group (Table 4). There was no significant increase in the stent thrombosis rates at 3 years in any of the studies. The patients included in these studies were on dual antiplatelet therapy for at least 12 months (Table 4).

\subsection{Safety}

Brachytherapy has been established to be a safe treatment modality for DES-ISR particularly in complex patients $[18,56,79,84,87]$.

The studies included in this review demonstrated VBT to be a safe procedure with high rate of immediate procedural success, no procedural adverse events in $>99 \%$ of the cases and minimal incidence of acute or subacute thrombosis $(<2.2 \%)$ at one year [18,22,35,81-85]. A recent review by Refahi et al. [88] demonstrated VBT to be safe and well tolerated treatment option in a high-risk patient population. A retrospective analysis by Ohri et al. [79] demonstrated VBT to be a safe treatment modality for DES-ISR with similarly low rates of procedural (VBT group 4.5\%, control group $0 \%, p=0.190$ ) and post-procedural (within 72 hours, $<5 \%$ in both groups) complications compared to PCI alone.

\section{Discussion}

This review compiles studies that specifically address the question of role of VBT for DES-ISR. Our review demonstrated VBT to be a safe and effective treatment modality for complex patients having multiple risk factors for DES-ISR. VBT may have improved clinical outcomes that include MACE, TVR, TLR and lower target lesion $\mathrm{MI}$ at 1 year compared to re-DES for DES-ISR and also multilayered ISR although there is paucity of data available. Our review demonstrated low rates of stent thrombosis in both VBT (0-2.1\%) and re-DES/non-IVBT groups $(0-1.5 \%)$ secondary to the use of DAPT for at least one year in both groups, hence preventing late stent thrombosis.

There are some inconsistencies between the definitions of MACE outcomes and MI in the eligible studies. These inconsistencies along with different inclusion and exclusion criteria render the lack of generalizability of the results (Tables 1,4) and it makes it challenging to compare the findings between studies. The criteria for MACE and MI need to be standardised across various studies to enable direct comparison of outcomes. Certain studies included patients who presented for VBT for DES-ISR with no exclusion criteria [82,83] whereas some studies excluded patients with features such as cardiogenic shock, stent thrombosis, STEMI or inability to take long term DAPT $[18,22,35,84,85]$ which could impact the findings.

The 2018 European Guidelines on Myocardial revascularization recommends re-DES and DCB for the management of DES-ISR with no role for vascular brachytherapy [39]. There is still a belief that DCB angioplasty could be less effective than repeat DES for DES-ISR [89]. A recent meta-analysis by Giacoppo et al. [89] compared DCB to repeat DES stenting for DES-ISR. They pooled individual patient data from the 10 randomized clinical trials comparing DCB with DES till date [89]. Their analysis demonstrated DCB angioplasty to be less effective than repeat DES implantation in the treatment of DES-ISR at 3 years [89]. The 
risk of primary safety endpoint which was a composite of all-cause death, MI, or target lesion thrombosis at 3 years was higher with the DCB angioplasty than with repeat DES implantation (20.3\% vs 13.4\%; hazard ratio [HR] 1.58, 95\% CI 1.16 to 2.13) [89]. Similarly, in the RIBS IV study, which compared 3-year safety and efficacy of drug eluting balloons (DEB) and EES in patients with DES-ISR, demonstrated reduced combined clinical outcome measure of cardiac death, MI and TLR in the EES arm compared to the DEB arm (19 [12.3\%] vs 31 [20.1\%]; $p=0.04$; HR 0.57 [95\% CI 0.34 to 0.96$]$ ), driven by a lower need for TLR (11 [7.1\%] vs 24 [15.6\%]; $p=0.015$; HR 0.43 [95\% CI 0.21 to 0.87 ]) [90]. However, the recently published results from the DEB-DRAGON-Registry which compared the 3year outcomes following thin-strut DES versus DEB for treatment of ISR demonstrated no significant differences in TLR (11.2\% vs $11.2 \%$; HR 0.91 [95\% CI 0.55 to 1.51 ], $p$ $=0.707)$, TVR (13.4\% vs $14.2 \%$; HR 0.86 [95\% CI 0.55 to $1.36], p=0.523$ ), and device oriented composite end point, defined as a composite of cardiac death, TLR and target vessel MI (14.2\% vs $14.2 \%$; HR 0.91 [ $95 \%$ CI 0.58 to 1.42 ], $p$ $=0.667$ ) between the thin-DES and DEB group at 3 years [91].

Vascular brachytherapy was once one of the primary strategies for management of ISR in both native coronary arteries and saphenous venous grafts (level I evidence) [37]. Its role diminished once drug eluting stents came into existence and proved to have better clinical outcomes compared to VBT. In this review, the rates of TVR ranged from 10 to $24 \%$ in patients with DES-ISR at one year (Table 4). The patients in the VBT group are generally sicker with more complex disease and hence it is not a fair comparison. The retrospective studies included in this review had very complex patients with multiple cardiac risk factors including hypertension ( $>75 \%$ of patients), dyslipidaemia ( $>80 \%$ of patients), prior CABG ( $>35 \%)$, smoking, diabetes $(>40 \%)$, high BMI and male gender (Table 2). They tend to have multiple layers of stents and hence we believe that the comparison of VBT to other modalities has been confounded by the complexity of the patients' receiving treatment. A recent systematic review and meta-analysis by Megaly et al. [7] demonstrated that out of the 917 patients included in their study, approximately $57 \%$ had three or more prior episodes of ISR before attempting VBT with about $50 \%$ of the patients included in their study having had prior CABG. However, our study makes an in-depth analysis of the reported morbidities, methodologies and outcomes and concurs with the findings of recently published meta-analysis. We believe that in the current DES era, DES-ISR is a challenging problem with very limited options for treatment whereby VBT could potentially prove to be an effective treatment modality. We are aware that modern brachytherapy techniques have developed to more accurate targeting capability and thereby reducing morbidity from this procedure and improving target coverage and outcomes. There- fore, when further studies eventuate these techniques will need to be clearly defined.

DES-ISR involves neointimal hyperplasia secondary to tissue injury caused by PCI and stent implantation within an arterial segment [64]. This cellular proliferation expands into the media and then further into the arterial lumen. VBT delivered locally targets this neoproliferative process [64]. To cover the detailed pathophysiology is beyond the scope of this review however we believe that VBT still has a role in this complex subset of patients. Currently, there are a few centres across the world that continue to utilise VBT for this complex subset of patients with DES-ISR [92,93]. Unfortunately, there is lack of long-term studies with no randomised studies comparing VBT to re-DES or DCB for DES-ISR. This is likely due to the practicality issues as outlined earlier in this review.

It is noted that patients with ISR require an urgent revascularisation procedure which can be challenging. There are alternative approaches to using VBT for these patients including either deferring the coronary intervention until the brachytherapy procedure or if the patient needs an urgent intervention, to perform balloon angioplasty alone (without a stent) and refer for staged brachytherapy within 7 to 10 days $[94,95]$. There have been publications of case reports recently whereby $\mathrm{VBT}$ has been used in patients with multiple prior DES-ISR, POBA, balloon angioplasty failure with good clinical response [96]. A recent study by Rawal et al. [97] has further demonstrated VBT to improve quality of life and patient reported outcomes in short and median term. There are generally significantly worse outcomes when VBT is combined with DES or BMS and hence this should be avoided [21].

\subsection{Cost effectiveness}

VBT can potentially prove to be a cost-effective treatment modality considering radiation therapy centres are expanding across the world with the radiation oncologist and the rest of the radiation delivery team (including radiation therapists, radiation oncology medical physicists, and nurses) present on site. Furthermore, the source required for vascular brachytherapy is available onsite as well. Hence, there is minimal additional cost involved to deliver vascular brachytherapy for DES-ISR. The most commonly used source for vascular brachytherapy in the included studies was the beta catheter system which does not require additional lab or staff shielding [21]. The beta radiation can only penetrate a very short distance in human tissues with no radioactivity detectable on the patient's body surface on routine surveillance scans during VBT [21].

\subsection{Imaging}

It is recommended that future randomised controlled trials use intravascular imaging, either intravascular ultrasound (IVUS) or optical coherence tomography (OCT). Intravascular imaging has an important role in guiding man- 
agement by providing important insights into the mechanism of DES-ISR [7]. As an adjunct to angiography, intravascular imaging provides tomographic assessment of lumen area, plaque size, distribution and composition [98]. IVUS detects the presence of neointimal hyperplasia within the stent, stent underexpansion, edge problems and stent fracture $[25,26,28,99]$. It can highlight whether the ISR is focal or diffuse which is a predictor for future reintervention $[29,99]$. OCT further provides a better axial resolution $(15 \mu \mathrm{m})$ compared to IVUS $(150 \mu \mathrm{m})$ to further assess this $[20,26]$. There has been some evidence to suggest that implantation of both multiple and long stents with PCI without IVUS is associated with higher rates of ISR [28]. Megaly et al. [80] found that the lesions treated with IVUS had lower incidence of TLR and a trend towards lower incidence of MACE compared to the lesions that were not treated with IVUS.

It is recommended that future trials include patients who can take DAPT for at least 12 months to prevent late stent thrombosis [80]. Furthermore, future trials will need to ensure longer length of irradiation to cover areas proximal and distal to the lesions to prevent geographic mismatch/higher incidence of edge restenosis [80].

\subsection{Limitations}

No long-term comparison of outcomes are available beyond 1 year between VBT and re-DES in the studies available. All of the studies are retrospective in nature and most of the studies are single centre studies. There is a lack of consistent measurement even when defining MACE across various studies which makes comparison of the studies challenging. In addition, there was limited use of intravascular ultrasound (IVUS) or intravascular optical coherence tomography (OCT) in studies reviewed despite its importance in determining the intravascular pathology at a tissue level.

We note the costs involved in setting up a centre for VBT however if a radiation therapy setup is already available at a centre, the additional cost involved for delivering VBT should be minimal.

\section{Conclusions}

Our review recognised VBT to be a safe and effective treatment modality for complex patients with multiple risk factors for DES-ISR. It may have a potential role in the future management of DES-ISR. VBT has been shown to be an effective and safe treatment strategy in complex patients with multiple risk factors for DES-ISR in initial reports.

There is limited evidence available from retrospective studies, long term ( $>5$ years) randomised controlled trials investigating the effectiveness of VBT compared to re-DES, with stringent inclusion and exclusion criteria, are warranted. Intravascular imaging (intravascular OCT/IVUS) must be utilised to determine the mechanism and guide management. The patients who present with
STEMI, cardiogenic shock or angiographic evidence of stent thrombosis with an inability to take DAPT should be excluded from future studies. Consistency in the definition of MACE and MI also needs to be established to enable objective comparison between studies. More randomised controlled trials are required to objectively assess the role of VBT compared to DES and drug coated balloons.

\section{Author contributions}

AM, SSD, DB and JD contributed to the design of the review. AM acquired the data and wrote the first detailed version of the draft. AM, SSD, JD and DB contributed to the detailed review of the literature. AM, SSD, JD and DB critically revised the intellectual content of this work.

\section{Ethics approval and consent to participate}

Not applicable.

\section{Acknowledgment}

We would like to thank all the peer reviewers for their opinions and suggestions.

\section{Funding}

This research received no external funding.

\section{Conflict of interest}

The authors declare no conflict of interest.

\section{Supplementary material}

Supplementary material associated with this article can be found, in the online version, at https://www.imrpre ss.com/journal/RCM/23/2/10.31083/j.rcm2302054.

\section{References}

[1] World Health Organization. Cardiovascular Diseases. 2020. Available at: https://www.who.int/health-topics/cardiovascular -diseases/\#tab=tab_1 (Accessed: 19 July 2020).

[2] Iqbal J, Gunn J, Serruys PW. Coronary stents: historical development, current status and future directions. British Medical Bulletin. 2013; 106: 193-211.

[3] World Health Organization. Cardiovascular Diseases (CVDs). 2017. Available at: https:/www.who.int/news-room/fact-she ets/detail/cardiovascular-diseases-(cvds) (Accessed: 19 July 2020).

[4] Khan MA, Hashim MJ, Mustafa H, Baniyas MY, Al Suwaidi SKBM, AlKatheeri R, et al. Global Epidemiology of Ischemic Heart Disease: Results from the Global Burden of Disease Study. Cureus. 2020; 12: e9349.

[5] Teirstein PS, Massullo V, Jani S, Popma JJ, Mintz GS, Russo $\mathrm{RJ}$, et al. Catheter-Based Radiotherapy to Inhibit Restenosis after Coronary Stenting. New England Journal of Medicine. 1997; 336: 1697-1703.

[6] Lemos PA, Hoye A, Goedhart D, Arampatzis CA, Saia F, van der Giessen WJ, et al. Clinical, Angiographic, and Procedural Predictors of Angiographic Restenosis after Sirolimus-Eluting Stent Implantation in Complex Patients: an evaluation from the Rapamycin-Eluting Stent Evaluated At Rotterdam Cardiology 
Hospital (RESEARCH) study. Circulation. 2004; 109: 13661370.

[7] Megaly M, Glogoza M, Xenogiannis I, Vemmou E, Nikolakopoulos I, Omer M, et al. Coronary intravascular brachytherapy for recurrent coronary drug-eluting in-stent restenosis: A systematic review and meta-analysis. Cardiovascular Revascularization Medicine. 2021; 23: 28-35.

[8] Chitkara K, Gershlick A. Second- versus first-generation Drugeluting Stents. Interventional Cardiology Review. 2010; 5: 23.

[9] Diodato M, Chedrawy EG. Coronary Artery Bypass Graft Surgery: the Past, Present, and Future of Myocardial Revascularisation. Surgery Research and Practice. 2014; 2014: 726158.

[10] Scheller B, Hehrlein C, Bocksch W, Rutsch W, Haghi D, Dietz $\mathrm{U}$, et al. Treatment of Coronary in-Stent Restenosis with a Paclitaxel-Coated Balloon Catheter. New England Journal of Medicine. 2006; 355: 2113-2124.

[11] Verin V, Urban P, Popowski Y, Schwager M, Nouet P, Dorsaz $\mathrm{PA}$, et al. Feasibility of intracoronary beta-irradiation to reduce restenosis after balloon angioplasty. A clinical pilot study. Circulation. 1997; 95: 1138-1144.

[12] Condado JA, Waksman R, Gurdiel O, Espinosa R, Gonzalez J, Burger B, et al. Long-term Angiographic and Clinical Outcome after Percutaneous Transluminal Coronary Angioplasty and Intracoronary Radiation Therapy in Humans. Circulation. 1997; 96: 727-732.

[13] King LA, Kastrati A, Byrne RA. Treatment of coronary drugeluting stent restenosis: a journey back to the future? Expert Review of Medical Devices. 2013; 10: 423-427.

[14] Siontis GCM, Stefanini GG, Mavridis D, Siontis KC, Alfonso F, Pérez-Vizcayno MJ, et al. Percutaneous coronary interventional strategies for treatment of in-stent restenosis: a network metaanalysis. The Lancet. 2015 ; 386: 655-664.

[15] Nakahama H, Jankowski M, Dixon SR, Abbas AE. Long-term outcome of brachytherapy treatment for coronary in-stent restenosis: Ten-year follow-up. Catheterization and Cardiovascular Interventions. 2019; 93: E211-E216.

[16] Sethi A, Malhotra G, Singh S, Singh PP, Khosla S. Efficacy of Various Percutaneous Interventions for in-Stent Restenosis: comprehensive network meta-analysis of randomized controlled trials. Circulation: Cardiovascular Interventions. 2015; 8: e002778.

[17] Waksman R, Iantorno M. Refractory in-Stent Restenosis: Improving Outcomes by Standardizing our Approach. Current Cardiology Reports. 2018; 20: 140.

[18] Bonello L, Kaneshige K, De Labriolle A, Roy P, Lemesle G, Torguson R, et al. Vascular Brachytherapy for Patients with Drug-Eluting Stent Restenosis. Journal of Interventional Cardiology. 2008; 21: 528-534.

[19] Alfonso F, García J, Pérez-Vizcayno M, Hernando L, Hernandez $\mathrm{R}$, Escaned $\mathrm{J}$, et al. New Stent Implantation for Recurrences after Stenting for in-Stent Restenosis: implications of a third metal layer in human coronary arteries. Journal of the American College of Cardiology. 2009; 54: 1036-1038.

[20] Her AY, Shin ES. Current Management of In-Stent Restenosis. Korean Circulation Journal. 2018; 48: 337-349.

[21] Chen Y, Buchanan KD, Chan RC, Zhang C, Torguson R, Satler LF, et al. Combined Vascular Brachytherapy and Stenting for the Treatment of in-Stent Restenosis. The American Journal of Cardiology. 2020; 125: 712-719.

[22] Maluenda G, Ben-Dor I, Gaglia MA, Wakabayashi K, Mahmoudi M, Sardi G, et al. Clinical Outcomes and Treatment after Drug-Eluting Stent Failure: the absence of traditional risk factors for in-stent restenosis. Circulation: Cardiovascular Interventions. 2012; 5: 12-19.

[23] Jukema JW, Ahmed TAN, Verschuren JJW, Quax PHA. Restenosis after PCI. Part 2: prevention and therapy. Nature Re- views Cardiology. 2012; 9: 79-90.

[24] Buchanan KD, Torguson R, Rogers T, Xu L, Gai J, Ben-Dor I, et al. In-Stent Restenosis of Drug-Eluting Stents Compared with a Matched Group of Patients with De Novo Coronary Artery Stenosis. The American Journal of Cardiology. 2018; 121: $1512-1518$.

[25] Dangas GD, Claessen BE, Caixeta A, Sanidas EA, Mintz GS, Mehran R. In-Stent Restenosis in the Drug-Eluting Stent Era. Journal of the American College of Cardiology. 2010; 56: 18971907.

[26] Alfonso F, Byrne RA, Rivero F, Kastrati A. Current Treatment of in-Stent Restenosis. Journal of the American College of Cardiology. 2014; 63: 2659-2673.

[27] Theodoropoulos K, Mennuni MG, Dangas GD, Meelu OA, Bansilal S, Baber U, et al. Resistant in-stent restenosis in the drug eluting stent era. Catheterization and Cardiovascular Interventions. 2016; 88: 777-785.

[28] Minha S, Pichard AD, Waksman R. In-stent restenosis of drugeluting stents. Future Cardiology. 2013; 9: 721-731.

[29] Cosgrave J, Melzi G, Biondi-Zoccai GGL, Airoldi F, Chieffo A, Sangiorgi GM, et al. Drug-Eluting Stent Restenosis: The Pattern Predicts the Outcome. Journal of the American College of Cardiology. 2006; 47: 2399-2404.

[30] Bavry AA, Bhatt DL. Appropriate use of drug-eluting stents: balancing the reduction in restenosis with the concern of late thrombosis. The Lancet. 2008; 371: 2134-2143.

[31] Mishra S, Wolfram RM, Torguson R, Chu WW, Xue Z, Gevorkian N, et al. Comparison of Effectiveness and Safety of Drug-Eluting Stents Versus Vascular Brachytherapy for Saphenous Vein Graft in-Stent Restenosis. The American Journal of Cardiology. 2006; 97: 1303-1307.

[32] Lepor NE, Madyoon H, Kereiakes D. Effective and efficient strategies for coronary revascularization in the drug-eluting stent era. Reviews in Cardiovascular Medicine. 2002; 3: S38-S50.

[33] Kaluza GL, Raizner AE. Brachytherapy for restenosis after stenting for coronary artery disease: its role in the drug-eluting stent era. Current Opinion in Cardiology. 2004; 19: 601-607.

[34] Colombo A, Moses JW, Morice MC, Ludwig J, Holmes DR, Spanos V, et al. Randomized Study to Evaluate SirolimusEluting Stents Implanted at Coronary Bifurcation Lesions. Circulation. 2004; 109: 1244-1249.

[35] Varghese MJ, Bhatheja S, Baber U, Kezbor S, Chincholi A, Chamaria $\mathrm{S}$, et al. Intravascular Brachytherapy for the Management of Repeated Multimetal-Layered Drug-Eluting Coronary Stent Restenosis. Circulation: Cardiovascular Interventions. 2018; 11: e006832.

[36] Mehran R, Dangas G, Abizaid AS, Mintz GS, Lansky AJ, Satler LF, et al. Angiographic Patterns of in-Stent Restenosis: classification and implications for long-term outcome. Circulation. 1999; 100: 1872-1878.

[37] Silber S, Albertsson P, Avilés FF, Camici PG, Colombo A, Hamm C, et al. Guidelines for Percutaneous Coronary Interventions: The Task Force for Percutaneous Coronary Interventions of the European Society of Cardiology. European Heart Journal. 2005; 26: 804-847.

[38] Task Force on Myocardial Revascularization of the European Society of C, the European Association for Cardio-Thoracic S, European Association for Percutaneous Cardiovascular I, Wijns W, Kolh P, Danchin N, et al. Guidelines on myocardial revascularization. European Heart Journal. 2010; 31: 2501-2555.

[39] Neumann FJ, Sousa-Uva M, Ahlsson A, Alfonso F, Banning AP, Benedetto U, et al. 2018 ESC/EACTS Guidelines on myocardial revascularization. European Heart Journal. 2019; 40: 87-165.

[40] Giacoppo D, Gargiulo G, Aruta P, Capranzano P, Tamburino C, Capodanno D. Treatment strategies for coronary in-stent restenosis: systematic review and hierarchical Bayesian network 
meta-analysis of 24 randomised trials and 4880 patients. British Medical Journal. 2015; 351: h5392.

[41] Pleva L, Kukla P, Kusnierova P, Zapletalova J, Hlinomaz O. Comparison of the Efficacy of Paclitaxel-Eluting Balloon Catheters and Everolimus-Eluting Stents in the Treatment of Coronary in-Stent Restenosis. Circulation: Cardiovascular Interventions. 2016; 9: e003316.

[42] Alfonso F, Pérez-Vizcayno MJ, Dutary J, Zueco J, Cequier A, García-Touchard A, et al. Implantation of a Drug-Eluting Stent with a Different Drug (Switch Strategy) in Patients with DrugEluting Stent Restenosis. Results from a prospective multicenter study (RIBS III [Restenosis Intra-Stent: Balloon Angioplasty Versus Drug-Eluting Stent]). JACC: Cardiovascular Interventions. 2012; 5: 728-737.

[43] Sinaga DA, Ho HH, Watson TJ, Sim A, Nyein TT, Jafary FH, et al. Drug-Coated Balloons: a Safe and Effective Alternative to Drug-Eluting Stents in Small Vessel Coronary Artery Disease. Journal of Interventional Cardiology. 2016; 29: 454-460.

[44] Nestelberger T, Jeger R. Drug-coated Balloons for Small Coronary Vessel Interventions: A Literature Review. Journal of Interventional Cardiology. 2019; 14: 131-136.

[45] Picard F, Doucet S, Asgar AW. Contemporary use of drugcoated balloons in coronary artery disease: where are we now? Archives of Cardiovascular Diseases. 2017; 110: 259-272.

[46] Reul RM. Will drug-eluting stents replace coronary artery bypass surgery? Texas Heart Institute Journal. 2005; 32: 323-330.

[47] Melly L, Torregrossa G, Lee T, Jansens J, Puskas JD. Fifty years of coronary artery bypass grafting. Journal of Thoracic Disease. 2018; 10: 1960-1967.

[48] Ariyaratne TV, Yap C, Ademi Z, Rosenfeldt F, Duffy SJ, Billah $\mathrm{B}$, et al. A systematic review of cost-effectiveness of percutaneous coronary intervention vs. surgery for the treatment of multivessel coronary artery disease in the drug-eluting stent era. European Heart Journal - Quality of Care and Clinical Outcomes. 2016; 2: 261-270.

[49] Magnuson EA, Farkouh ME, Fuster V, Wang K, Vilain K, Li $\mathrm{H}$, et al. Cost-Effectiveness of Percutaneous Coronary Intervention with Drug Eluting Stents Versus Bypass Surgery for Patients with Diabetes Mellitus and Multivessel Coronary Artery Disease. Circulation. 2013; 127: 820-831.

[50] Cohen DJ, Osnabrugge RL, Magnuson EA, Wang K, Li H, Chinnakondepalli $\mathrm{K}$, et al. Cost-Effectiveness of Percutaneous Coronary Intervention with Drug-Eluting Stents Versus Bypass Surgery for Patients with 3-Vessel or Left Main Coronary Artery Disease: final results from the Synergy Between Percutaneous Coronary Intervention With TAXUS and Cardiac Surgery (SYNTAX) trial. Circulation. 2014; 130: 1146-1157.

[51] Dorenkamp M, Boldt J, Leber AW, Sohns C, Roser M, Boldt L, et al. Cost-Effectiveness of Paclitaxel-Coated Balloon Angioplasty in Patients with Drug-Eluting Stent Restenosis. Clinical Cardiology. 2013; 36: 407-413.

[52] Serruys PW, Ormiston J, van Geuns R, de Bruyne B, Dudek D, Christiansen E, et al. A Polylactide Bioresorbable Scaffold Eluting Everolimus for Treatment of Coronary Stenosis: 5-Year Follow-Up. Journal of the American College of Cardiology. 2016; 67: 766-776.

[53] Alfonso F, Cuesta J, Pérez-Vizcayno MJ, García del Blanco B, Rumoroso JR, Bosa F, et al. Bioresorbable Vascular Scaffolds for Patients with in-Stent Restenosis: The RIBS VI Study. JACC: Cardiovascular Interventions. 2017; 10: 1841-1851.

[54] Ni L, Chen H, Luo Z, Yu Y. Bioresorbable vascular stents and drug-eluting stents in treatment of coronary heart disease: a meta-analysis. Journal of Cardiothoracic Surgery. 2020; 15: 26.

[55] Mukherjee D, Moliterno DJ. Brachytherapy for in-Stent Restenosis: A Distant Second Choice to Drug-Eluting Stent Placement. The Journal of the American Medical Association.
2006; 295: 1307.

[56] Kuiper KKJ, Salem M, Rotevatn S, Mills J, Nordrehaug JE. Implementing a best-treatment strategy with intracoronary brachytherapy for in-stent restenosis in patients at high risk for recurrence. Cardiovascular Revascularization Medicine. 2007; 8: 9-14.

[57] Teirstein PS, King S. Vascular Radiation in a Drug-Eluting Stent World: it's not over till it's over. Circulation. 2003; 108: 384385.

[58] Krotz F, Sohn H, Klauss V, Schiele T. Intracoronary Brachytherapy - Clinical State and Pathophysiological Considerations. Current Pharmaceutical Design. 2005; 11: 421-433.

[59] Uchida T, Bakhai A, Almonacid A, Shibata T, Cox B, Kuntz RE. A meta-analysis of randomized controlled trials of intracoronary gamma- and beta-radiation therapy for in-stent restenosis. Heart and Vessels. 2006; 21: 368-374.

[60] Shirai K, Lansky AJ, Mintz GS, Costantini CO, Fahy M, Mehran $\mathrm{R}$, et al. Comparison of the angiographic outcomes after beta versus gamma vascular brachytherapy for treatment of in-stent restenosis. The American Journal of Cardiology. 2003; 92: 1409-1413.

[61] Li XJ, Rha SW, Wani SP, Wang L, Poddar KL, Oh DJ. Vascular brachytherapy revisited for in-stent restenosis in the drug-eluting stent era: current status and future perspective. Chinese Medical Journal. 2009; 122: 2174-2179.

[62] Thomas MR. Brachytherapy: here today, gone tomorrow? Heart. 2005; 91: iii32-iii34.

[63] Waksman R. Intracoronary brachytherapy in the cath lab. Physics dosimetry, technology and safety considerations. Herz. 1998; 23: 401-406.

[64] Williams DO, Sobieszczyk P. Coronary Brachytherapy 2016. JACC: Cardiovascular Interventions. 2016; 9: 1266-1268.

[65] Zahn R, Hamm CW, Zeymer U, Richardt G, Kelm M, Levenson $\mathrm{B}$, et al. Coronary stenting with the sirolimus-eluting stent in patients with restenosis after intracoronary brachytherapy: results from the prospective multicentre German Cypher Stent Registry. Clinical Research in Cardiology. 2010; 99: 99-106.

[66] Saia F, Lemos PA, Sianos G, Degertekin M, Lee C, Arampatzis CA, et al. Effectiveness of sirolimus-eluting stent implantation for recurrent in-stent restenosis after brachytherapy. The American Journal of Cardiology. 2003; 92: 200-203.

[67] Reynolds MR, Pinto DS, Shi C, Walczak J, Berezin R, Holmes DR, et al. Cost-effectiveness of sirolimus-eluting stents compared with vascular brachytherapy for the treatment of in-stent restenosis. American Heart Journal. 2007; 154: 1221-1227.

[68] Feres F, Muñoz JS, Abizaid A, Albertal M, Mintz GS, Staico $\mathrm{R}$, et al. Comparison between Sirolimus-Eluting Stents and Intracoronary Catheter-Based Beta Radiation for the Treatment of in-Stent Restenosis. The American Journal of Cardiology. 2005; 96: 1656-1662.

[69] Benjo A, Cardoso RN, Collins T, Garcia D, Macedo FY, ElHayek G, et al. Vascular brachytherapy versus drug-eluting stents in the treatment of in-stent restenosis: a meta-analysis of long-term outcomes. Catheterization and Cardiovascular Interventions. 2016; 87: 200-208.

[70] Daemen J, Wenaweser P, Tsuchida K, Abrecht L, Vaina S, Morger $\mathrm{C}$, et al. Early and late coronary stent thrombosis of sirolimus-eluting and paclitaxel-eluting stents in routine clinical practice: data from a large two-institutional cohort study. The Lancet. 2007; 369: 667-678.

[71] Iakovou I. Thrombosis after stent implantation: how much of a problem is there? Future Cardiology. 2008; 4: 261-267.

[72] Waksman R, Ajani AE, White RL, Pinnow E, Dieble R, Bui $\mathrm{AB}$, et al. Prolonged antiplatelet therapy to prevent late thrombosis after intracoronary gamma-radiation in patients with in-stent restenosis: Washington Radiation for In-Stent Restenosis Trial 
plus 6 months of clopidogrel (WRIST PLUS). Circulation. 2001; 103: 2332-2335.

[73] Ortolani P, Marzocchi A, Aquilina M, Gaiba W, Neri S, Marrozzini C, et al.32P Brachytherapy in the Treatment of Complex Cypher in-Stent Restenosis. Journal of Interventional Cardiology. 2005; 18: 205-211.

[74] Nikolakopoulos I, Vemmou E, Xenogiannis I, Brilakis ES. Combined use of intravascular lithotripsy and brachytherapy: a new approach for the treatment of recurrent coronary in-stent restenosis. Catheterization and Cardiovascular Interventions. 2021; 97: 1402-1406.

[75] Price MJ, Giap H, Teirstein PS. Intracoronary radiation therapy for multi-drug resistant in-stent restenosis: Initial clinical experience. Catheterization and Cardiovascular Interventions. 2007; 69: 132-134

[76] Kim Y, Lee B, Park D, Park K, Choi B, Lee CW, et al. Comparison with Conventional Therapies of Repeated Sirolimus-Eluting Stent Implantation for the Treatment of Drug-Eluting Coronary Stent Restenosis. The American Journal of Cardiology. 2006; 98: 1451-1454.

[77] Moussa ID, Moses JW, Kuntz RE, Holmes DR, Popma JJ, Teirstein PS, et al. The Fate of Patients with Clinical Recurrence after Sirolimus-Eluting Stent Implantation (a Two-Year Followup Analysis from the SIRIUS Trial). The American Journal of Cardiology. 2006; 97: 1582-1584.

[78] Mishkel GJ, Moore AL, Markwell S, Shelton MC, Shelton ME. Long-Term Outcomes after Management of Restenosis or Thrombosis of Drug-Eluting Stents. Journal of the American College of Cardiology. 2007; 49: 181-184.

[79] Ohri N, Sharma S, Kini A, Baber U, Aquino M, Roy S, et al. Intracoronary brachytherapy for in-stent restenosis of drug-eluting stents. Advances in Radiation Oncology. 2016; 1: 4-9.

[80] Megaly M, Glogoza M, Xenogiannis I, Vemmou E, Nikolakopoulos I, Willson L, et al. Outcomes of intravascular brachytherapy for recurrent drug-eluting in-stent restenosis. Catheterization and Cardiovascular Interventions. 2020; 97: 32 38.

[81] Megaly M, Glogoza M, Xenogiannis I, Vemmou E, Nikolakopoulos I, Omer M, et al. Outcomes with combined laser atherectomy and intravascular brachytherapy in recurrent drugeluting in-stent restenosis. Cardiovascular Revascularization Medicine. 2020; 22: 29-33.

[82] Mangione FM, Jatene T, Badr Eslam R, Bergmark BA, Gallagher JR, Shah PB, et al. Usefulness of Intracoronary Brachytherapy for Patients with Resistant Drug-Eluting Stent Restenosis. The American Journal of Cardiology. 2017; 120: 369-373.

[83] Meraj PM, Patel K, Patel A, Doshi R, Srinivas G, Jauhar R, et al. Northwell intracoronary brachytherapy for the treatment of recurrent drug eluting stent in-stent restenosis (NITDI study group). Catheterization and Cardiovascular Interventions. 2021; 97: 41-46.

[84] Negi SI, Torguson R, Gai J, Kiramijyan S, Koifman E, Chan R, et al. Intracoronary Brachytherapy for Recurrent Drug-Eluting Stent Failure. JACC: Cardiovascular Interventions. 2016; 9: 1259-1265.

[85] Torguson R, Sabate M, Deible R, Smith K, Chu WW, Kent KM, et al. Intravascular Brachytherapy Versus Drug-Eluting Stents for the Treatment of Patients with Drug-Eluting Stent Restenosis. The American Journal of Cardiology. 2006; 98: 1340-1344.
[86] Thygesen K, Alpert JS, Jaffe AS, Simoons ML, Chaitman BR, White HD, et al. Third universal definition of myocardial infarction. Circulation. 2012; 126: 2020-2035.

[87] Seabra Gomes R, de Araújo Gonçalves P, Campante Teles R, de Sousa Almeida M. Late results ( $>10$ years) of intracoronary beta brachytherapy for diffuse in-stent restenosis. Revista Portuguesa De Cardiologia (English Edition). 2014; 33: 609-616.

[88] Refahi S, Mohammadi M. Overview of Intracoronary Brachytherapy for the In-stent Restenosis of a Drug-Eluting Stent. Journal of Cardiovascular Medicine. 2019; 7: 400-405.

[89] Giacoppo D, Alfonso F, Xu B, Claessen B, Adriaenssens T, Jensen C, et al. Drug-Coated Balloon Angioplasty Versus DrugEluting Stent Implantation in Patients With Coronary Stent Restenosis. Journal of the American College of Cardiology. 2020; 75: 2664-2678.

[90] Alfonso F, Perez-Vizcayno MJ, Cuesta J, Garcia Del Blanco B, Garcia-Touchard A, Lopez-Minguez JR, et al. 3-Year Clinical Follow-Up of the RIBS IV Clinical Trial: A Prospective Randomized Study of Drug-Eluting Balloons Versus EverolimusEluting Stents in Patients With In-Stent Restenosis in Coronary Arteries Previously Treated With Drug- Eluting Stents. JACC: Cardiovascular Interventions. 2018; 11: 981-991.

[91] Wańha W, Bil J, Januszek R, Gilis-Malinowska N, Figatowski $\mathrm{T}$, Milewski M, et al. Long-Term Outcomes Following DrugEluting Balloons Versus Thin-Strut Drug-Eluting Stents for Treatment of in-Stent Restenosis (DEB-Dragon-Registry). Circulation: Cardiovascular Interventions. 2021; 14: e010868.

[92] The Heart Institute. Brachytherapy Florida: The Heart Institute. 2020. Available at: https://theheartinst.com/our-programs/coro nary-interventions/brachytherapy.dot (Accessed: 5 July 2020).

[93] Beaumont Health. Treatment of Coronary Restenosis - Restenosis Process in Heart Disease. 2020. Available at: https://www. beaumont.org/treatments/coronary-brachytherapy (Accessed: 5 July 2020).

[94] Avril T. When stents don't work for blocked arteries, targeted radiation may help: The Philadelphia Inquirer. 2017. Available at: https://www.inquirer.com/philly/health/hearthealth/When-s tents-dont-work-for-blocked-arteries-targeted-radiation-may -help.html (Accessed: 5 July 2020).

[95] Franklin B, Hanze 1G, Safian R, Timmis S. Heart and Vascular Update For Physicians 2015. Available at: https://issuu.co $\mathrm{m} /$ beaumonthospitals/docs/beaumont_h_v_news_issue $12 / 2$ (Accessed: 5 July 2020).

[96] Radiation for Refractory Restenosis via the Radial Route: Compatibility of Coronary Brachytherapy With Transradial Access [Internet]. CathLab Digest. 2018. Available at: https: //www.cathlabdigest.com/article/Radiation-Refractory-Reste nosis-Radial-Route-Compatibility-Coronary-Brachytherapy (Accessed: 6 November 2020).

[97] Rawal S, Sawant AC, Sridhar M, Chaudhry M, Sridhara S, Distler E, et al. Impact of intravascular brachytherapy on patient reported outcomes in patients with coronary artery disease. Cardiovascular Revascularization Medicine. 2020; 21: 1550-1554.

[98] Nissen SE, Yock P. Intravascular Ultrasound: novel pathophysiological insights and current clinical applications. Circulation. 2001; 103: 604-616.

[99] Kim SW, Mintz GS, Escolar E, Ohlmann P, Pregowski J, Tyczynski $\mathrm{P}$, et al. An intravascular ultrasound analysis of the mechanisms of restenosis comparing drug-eluting stents with brachytherapy. The American Journal of Cardiology. 2006; 97 : 1292-1298. 